\title{
Energy devices safety and impact on video- assisted thoracoscopic lung lobectomy postoperative course: monopolar electrocautery versus ultrasonic dissector
}

Maria Cattoni, Nicola Rotolo, Elisa Nardecchia, Silvia De Maio, Lorenzo Dominioni and Andrea Imperatori* (D)

\begin{abstract}
Background: This study aims to compare safety and impact of monopolar electrocautery and ultrasonic dissector (Harmonic ACE Plus ${ }^{\circledR}$ ) on postoperative short-term outcomes after video-assisted thoracoscopic (VATS) lobectomy and lymphadenectomy for lung cancer.
\end{abstract}

Methods: We analyzed the prospectively collected data of 140 consecutive patients [59\% male; median age: 71(IQR: 62-76) years] undergoing VATS lobectomy and lymphadenectomy in our institution between October 2016 and November 2019. Patients were divided in two groups based on device used: monopolar electric hook in 79 cases (Group A); ultrasonic dissector in 61(Group B). Energy instrument-related intraoperative accidents, hemothorax/ chylothorax incidence, total pleural effusion volume at 48 postoperative hours and chest tube duration were compared between groups. Multivariable analysis was performed to test energy device as possible independent risk factor either for increased pleural effusion volume or for prolonged chest tube duration.

Results: No intraoperative accidents due to energy device occurred. No hemothorax was recorded. Postoperative chylothorax incidence was slightly higher in Group A ( $2.5 \% \mathrm{vs} 0 \% ; p$-value $=0.21)$. Total pleural effusion volume at $48 \mathrm{~h}$ was significantly higher in Group B: $400(285-500)$ vs $255(150-459) \mathrm{ml}(p$-value $=0.005)$. Chest tube duration was similar in the two groups: $5(3-9)$ vs $5(3-8)$ days ( $p$-value $=0.77$ ). At multivariable analysis the energy device used was not associated with increased pleural effusion volume $(p$-value $=0.43)$ nor with prolonged chest tube duration $(p$ value $=0.28$.

Conclusions: Monopolar electrocautery and Harmonic ACE Plus ${ }^{\circledast}$ were safe and had a similar impact on short-term outcomes after VATS lobectomy and lymphadenectomy, suggesting that energy devices choice could be left to surgeon's preference.

Keywords: VATS lobectomy, Energy device, Monopolar electrocautery, Ultrasonic dissector, Postoperative outcomes, Non-small cell lung cancer

\footnotetext{
* Correspondence: andrea.imperatori@uninsubria.it

Center for Thoracic Surgery and Center for Minimally Invasive Surgery,

Department of Medicine and Surgery, University of Insubria, Via Guicciardini

9, 21100 Varese, Italy
}

(c) The Author(s). 2021 Open Access This article is licensed under a Creative Commons Attribution 4.0 International License, which permits use, sharing, adaptation, distribution and reproduction in any medium or format, as long as you give appropriate credit to the original author(s) and the source, provide a link to the Creative Commons licence, and indicate if changes were made. The images or other third party material in this article are included in the article's Creative Commons licence, unless indicated otherwise in a credit line to the material. If material is not included in the article's Creative Commons licence and your intended use is not permitted by statutory regulation or exceeds the permitted use, you will need to obtain permission directly from the copyright holder. To view a copy of this licence, visit http://creativecommons.org/licenses/by/4.0/. The Creative Commons Public Domain Dedication waiver (http://creativecommons.org/publicdomain/zero/1.0/) applies to the data made available in this article, unless otherwise stated in a credit line to the data. 


\section{Background}

In thoracic surgery, the introduction over the last two decades of a variety of energy devices together with endoscopic staplers has allowed to perform major videoassisted thoracoscopic (VATS) procedures under safe conditions and has increased the number of surgical interventions performed by mini-invasive approach.

Focusing on VATS lung lobectomy and lymphadenectomy, energy tools such as electric hook (monopolar energy), Harmonic ACE Plus (ultrasound energy), LigaSure ${ }^{\text {tm }}$ (bipolar energy), Enseal ${ }^{\circ}$ (bipolar energy) and Thunderbeat (ultrasound energy+ bipolar energy) are commonly used during pleural adhesiolysis, hilar dissection, small vessel sealing and lymph node removal [1-10]. However, to date the available information is insufficient to establish the superiority of any of these devices in enhancing the postoperative course after this type of procedure [4-6]. To our best knowledge, no study has directly compared the effect of traditional monopolar electric tools and of advanced ultrasonic dissectors on patients' course after VATS major lung resections.

This study aims to compare surgical monopolar electric hook vs Harmonic ACE Plus in terms of safety and impact on short-term postoperative outcomes after VATS lobectomy and lymph node dissection for nonsmall cell lung cancer.

\section{Methods}

We analyzed the prospectively collected data of consecutive patients who underwent VATS lung lobectomy and lymphadenectomy in our center from October 1st 2016 to November 30th 2019. We excluded: patients with benign disease or lung metastases; those requiring conversion to thoracotomy; those undergoing extended resection to chest wall, mediastinum or another lung lobe and those requiring the use of both monopolar electric hook and Harmonic ACE Plus energy device.

This study was approved by our University Hospital Ethic Committee and individual patient consent was obtained for each case.

All lung lobectomies and lymph node dissections were performed using a standardized three-port anterior approach [11]. Three experienced surgeons who had completed the learning curve for VATS lobectomy and lymphadenectomy carried out all surgeries as first operator. A 28 French chest tube was left in place after surgery until no air-leak was observed and effusion quantity was $\leq 250 \mathrm{ml} /$ day. Postoperatively all patients were managed according to our protocol: perioperative respiratory physiotherapy; epidural analgesia/paravertebral block in association with non-steroid analgesics; heparin antithrombotic prophylaxis; intravenous fluid restriction; early oral feeding; early urinary catheter removal, early ambulation.
For each patient we collected the following data: age, gender, body mass index (BMI), smoking habit, forced expiratory volume in $1 \mathrm{~s}\left(\mathrm{FEV}_{1}\right)$, comorbidities, type of lobectomy, pleural adhesiolysis, surgery duration, tumor size, tumor histology and pathological stage according to the 8th edition TNM staging system, number of dissected lymph nodes, total pleural effusion volume during the first 48 postoperative hours, postoperative chest tube stay, postoperative length of stay, 30-day postoperative complications and cost of instruments used during surgery (energy devices, staplers, cartridges, clips).

Patients were divided in two groups based on the device used for tissue dissection: the electric hook (Group A) or the Harmonic ACE Plus ${ }^{\ominus}$ (Group B). Use of either instrument was left up to surgeon's preference after intraoperative case evaluation; surgeons did not routinely use the same type of energy device.

Primary outcome was to assess and compare the safety of electric hook and Harmonic ACE Plus ${ }^{\circ}$ during the surgical procedure. Secondary endpoint was to compare the impact of these instruments on postoperative course, using as benchmarks: postoperative hemo/chylothorax incidence, pleural effusion volume during the first 48 postoperative hours and postoperative chest tube duration.

Univariable and multivariable analyses were performed in order to test the energy device as possible independent risk factor for increased pleural effusion volume during the first 48 postoperative hours and for prolonged postoperative chest tube duration. Factors analyzed were age, gender, BMI, cardiac comorbidities, pleural adhesiolysis, type of resection (upper/middle lobe lobectomy vs lower lobe lobectomy), tumor characteristics (size and histology), number of resected lymph nodes, energy device used (Harmonic ACE Plus ${ }^{\circ}$ versus electric hook), surgery duration, postoperative persistent air-leak $(>5$ days after surgery).

To limit the influence of possible confounding factors on final results, a propensity matched analysis was performed using the following parameters for matching: gender, site of resection, surgeon. Primary and secondary outcomes were analyzed and compared in the matched cohort.

Continuous data were reported as median with interquartile range (IQR) and compared using T-test for normally distributed data and Mann-Whitney $U$ test for non-normally distributed data. Categorical and count data were presented as frequencies and percentages and compared using Chi-square test or Fisher's exact test if any expected frequency was less than 5 . Univariable and multivariable analyses were performed by binary logistic regression, using as dependent variable cut-off value its overall median value. Multivariable analysis included only those variables that were statistically significant in univariate analysis. A $p$-value $<0.05$ was considered 
significant. Statistical analysis was performed using SPSS 24.0 software (IBM Corp, Armonk, NY, USA).

\section{Results}

During the study period 206 patients underwent lung lobectomy in our center. Of these, 66 patients were excluded from study: 44 patients were approached by thoracotomy, 10 underwent surgery for inflammatory disease or lung metastases, 7 required conversion from VATS to thoracotomy (4, intraoperative bleeding unrelated to energy devices; 2, locally advanced disease; 1 , lung failure to collapse) and in 5 cases surgeon used both devices.

Thus, 140 patients undergoing VATS lung lobectomy and lymphadenectomy for non-small cell lung cancer were left for statistical analysis. Tissue and lymph nodes dissection were performed by electric hook in 79 cases (Group A) and by Harmonic ACE Plus in 61 (Group B).

Patients' clinical, surgical and pathological data are listed and compared between Group A and Group B in Table 1.
Focusing on our primary outcome, no intraoperative complications due to energy device were recorded in both groups.

Surgical procedure lasted longer in Group B than in Group A: 216 (IQR: 193-265) vs 180 (IQR: 163-221) minutes, respectively ( $p$-value $<0.001)$. The costs of instruments used during surgery was significantly higher in Group B than in Group A [2063.60 (IQR: 1775,07$2352,13)$ vs 2390.49 (IQR: 2137,34-2636.93) €, respectively $(p$-value $<0.001)$, with no difference in terms of number of staplers and cartridges used.

Overall 30-day mortality was 0.7\%: 1 patient in Group A died of pulmonary embolism on postoperative day 15 . However, the 30-day mortality difference between the two groups was not statistically different (Group A vs Group B: $1.3 \%$ vs $0 \%$; $p$-value $=1.00$ ).

Overall 30-day morbidity was 35\% (49/140), with 5.7\% (8/140) patients presenting more than one complication. During postoperative stay, 30/140 (21\%) patients developed persistent air leak (> 5 days), 10 (7\%) pneumonia, 11 (8\%) atrial fibrillation, 2 (1\%) chylothorax, 1 empyema $(<1 \%), 1$ transient dysphonia $(<1 \%)$ and 1 abdominal

Table 1 Patients' characteristics: comparison between group A (monopolar electric hook) and group B (harmonic ACE plus ${ }^{\circledR}$ )

\begin{tabular}{|c|c|c|c|}
\hline Patients' characteristics & $\begin{array}{l}\text { Group A } \\
(n=79)\end{array}$ & $\begin{array}{l}\text { Group B } \\
(n=61)\end{array}$ & $p$-value \\
\hline Age, median (IQR) years & $69(62-75)$ & $72(64-76)$ & 0.56 \\
\hline Male, n (\%) & $41(52)$ & $42(69)$ & 0.043 \\
\hline BMI, median (IQR) kg/m² & $25(22-28)$ & $26(24-29)$ & 0.58 \\
\hline Current or former smoker, $\mathrm{n}(\%)$ & $58(73)$ & $47(77)$ & 0.62 \\
\hline $\mathrm{FEV}_{1}$, median (IQR) \% of predicted & $99(83-112)$ & $106(90-119)$ & 0.16 \\
\hline COPD, n (\%) & $15(19)$ & $15(25)$ & 0.42 \\
\hline Cardiac comorbidity, n (\%) & $24(30)$ & $14(23)$ & 0.33 \\
\hline Diabetes, n (\%) & $11(14)$ & $11(18)$ & 0.51 \\
\hline Previous malignancy, n (\%) & $29(37)$ & $17(28)$ & 0.27 \\
\hline Pleural adhesiolysis, n (\%) & $21(31)$ & $19(37)$ & 0.51 \\
\hline Lower lobe lobectomy, n (\%) & $22(28)$ & $31(51)$ & 0.005 \\
\hline Number of excised lymph nodes, median (IQR) & $8(6-11)$ & $9(5-13)$ & 0.20 \\
\hline Intraoperative blood loss $\geq 100$ ml, n (\%) & $15(23)$ & $14(33)$ & 0.26 \\
\hline Tumor size, median (IQR) cm & $1.8(1.5-2.8)$ & $1.9(1.5-3.0)$ & 0.76 \\
\hline Tumor histology, n (\%) & & & 0.76 \\
\hline Adenocarcinoma & $52(66)$ & $45(74)$ & \\
\hline Squamous cell carcinoma & $12(15)$ & $9(15)$ & \\
\hline Neuroendocrine tumor & $12(15)$ & $5(8)$ & \\
\hline Other histologies & $3(4)$ & $2(3)$ & \\
\hline Pathological stage, n (\%) & & & 0.80 \\
\hline । & $60(76)$ & $49(80)$ & \\
\hline$\|$ & $15(19)$ & $8(13)$ & \\
\hline III & $4(5)$ & $4(7)$ & \\
\hline
\end{tabular}


aortic occlusion $(<1 \%)$. No difference was detected comparing 30-day postoperative morbidity between Group A and Group B ( $32 \%$ vs $39 \%$ respectively; $p$-value $=0.34)$. Notably, the incidence of postoperative prolonged airleak was similar in the two groups ( $23 \%$ vs $25 \%$, respectively, $p$-value $=0.42$ ).

Regarding secondary outcomes benchmarks, no postoperative hemothorax was reported in both groups. Chylothorax incidence was slightly higher in Group A $(2.5 \%$ vs $0 \%$ Group B; $p$-value $=0.21$ ).

Pleural effusion volume during the first 48 postoperative hours was significantly lower in Group A than in Group B: 255 (IQR: 150-459) vs 400 (IQR: 285-500) ml, respectively; $p$-value $=0.005$. However, chest tube duration was similar in the two groups: 5 (IQR: $3-9$ ) vs 5 (IQR: 3-8) days, respectively; $p$-value $=0.77$. Likewise, there was no difference in terms of postoperative length of stay between Group A and Group B: 7 (IQR: 5-10) vs 7 (IQR: $5-10$ ) days; $p$-value $=0.61$.

At multivariable analysis, the type of energy device was not independently associated with increased total pleural effusion volume at 48 postoperative hours (Table 2), nor with prolonged postoperative chest tube duration (Table 3).

A total of 140 patients were eligible for propensity score matching analysis. The matched sample included 56 patients: 28 from Group A and 28 from Group B. No difference in terms of primary and secondary outcomes was detected in the matched cohort, as shown in Table 4.

\section{Discussion}

We focused on comparing the traditional monopolar electric hook and the advanced ultrasonic Harmonic ACE Plus ${ }^{\circ}$ dissector for VATS lung lobectomy and lymphadenectomy for non-small cell lung cancer, in terms of intraoperative safety and patients' postoperative course.

In our cohort no intraoperative complication due to energy devices was recorded, confirming the rarity of these injuries (1-2 cases per 1000 surgical procedures) [12]. Thermal burn is the most common cause of instrument-related injury and death during surgery and it is correlated with the device lateral thermal spread [13-17]. Monopolar electrocautery is generally associated with greater heat spread when compared to the advanced energy devices [13-17]. However, in our cohort no clinically relevant lesions to nerves or vessels occurred during surgery either using the monopolar electrocautery or the ultrasonic dissector. This suggests that surgeon awareness of energy device technology, application and common injury patterns, and the use of protected-tip cautery, may minimize complications related to energy-based instruments application for VATS lobectomy and lymphadenectomy $[14,16]$.

Postoperatively, no statistically significant difference of chylothorax incidence, chest tube duration and length of stay was detected between electric hook and Harmonic ACE Plus ${ }^{\circ}$, despite the increased postoperative pleural drainage in the ultrasonic dissector group that was not confirmed in the matched cohort. Moreover, energy device was not recognized as an independent risk factor of increased postoperative pleural effusion volume, and of prolonged chest tube duration.

Lack of significant differences in postoperative chylothorax and hemothorax incidence between monopolar electrocautery and ultrasonic dissector are consistent with results reported in the literature. Martucci et al., in their prospective randomized study of 119 patients undergoing open lung lobectomy and lymphadenectomy

Table 2 Risk factors for increased (> $320 \mathrm{ml}$ ) pleural effusion volume during the first 48 postoperative hours

\begin{tabular}{|c|c|c|c|c|}
\hline \multirow[t]{2}{*}{ Risk factors } & \multirow{2}{*}{$\begin{array}{l}\text { Univariable analysis } \\
\text { HR }(95 \% \mathrm{Cl})\end{array}$} & \multicolumn{3}{|c|}{ Multivariable analysis } \\
\hline & & $p$-value & $\mathrm{HR}(95 \% \mathrm{Cl})$ & $p$-value \\
\hline Age (continuous) & $1.00(0.97-1.04)$ & 0.89 & - & - \\
\hline Gender (male vs female) & $2.47(1.22-4.99)$ & 0.012 & $1.62(0.74-3.57)$ & 0.23 \\
\hline BMI (continuous) & $0.98(0.91-1.06)$ & 0.62 & - & - \\
\hline Cardiac comorbidities (none vs yes) & $1.72(0.80-3.70)$ & 0.16 & - & - \\
\hline Pleural adhesiolysis (none vs yes) & $1.22(0.57-2.61)$ & 0.61 & - & - \\
\hline Site of resection (upper/middle vs lower) & $3.95(1.90-8.25)$ & $<0.001$ & $3.10(1.42-6.78)$ & 0.004 \\
\hline Tumor size (continuous) & $0.99(0.77-1.28)$ & 0.96 & - & - \\
\hline Tumor histology (adenocarcinoma vs others) & $1.17(0.57-2.42)$ & 0.67 & - & - \\
\hline$N^{\circ}$ of resected lymph nodes (continuous) & $1.04(0.97-1.12)$ & 0.23 & - & - \\
\hline Energy device (ultrasonic vs monopolar) & $0.39(0.20-0.79)$ & 0.008 & $0.73(0.33-1.61)$ & 0.43 \\
\hline Surgery duration (continuous) & $1.01(1.01-1.02)$ & $<0.001$ & $1.01(1.00-1.02)$ & 0.024 \\
\hline Postoperative air-leak> 5 days (none vs yes) & $1.44(0.64-3.25)$ & 0.39 & - & - \\
\hline
\end{tabular}

$B M I$ body mass index, $\mathrm{Cl}$ confidence interval, $H R$ hazard ratio 
Table 3 Risk factors for prolonged (> 4 days) postoperative chest tube duration

\begin{tabular}{|c|c|c|c|c|}
\hline \multirow[t]{2}{*}{ Risk factors } & \multirow{2}{*}{$\begin{array}{l}\text { Univariable analysis } \\
\mathrm{HR}(95 \% \mathrm{Cl})\end{array}$} & \multicolumn{3}{|c|}{ Multivariable analysis } \\
\hline & & $p$-value & HR $(95 \% \mathrm{Cl})$ & $p$-value \\
\hline Age (continuous) & $1.04(1.00-1.08)$ & 0.033 & $1.03(1.00-1.07)$ & 0.07 \\
\hline Gender (male vs female) & $2.67(1.33-5.34)$ & 0.006 & $2.47(1.22-5.01)$ & 0.012 \\
\hline BMI (continuous) & $0.94(0.87-1.02)$ & 0.13 & - & - \\
\hline Cardiac comorbidities (none vs yes) & $1.14(0.54-2.41)$ & 0.73 & - & - \\
\hline Pleural adhesiolysis (none vs yes) & $1.84(0.85-4.00)$ & 0.12 & - & - \\
\hline Site of resection (upper/middle vs lower) & $1.63(0.82-3.26)$ & 0.17 & - & - \\
\hline Tumor size (continuous) & $1.14(0.87-1.49)$ & 0.35 & - & - \\
\hline Tumor histology (adenocarcinoma vs others) & $1.80(0.86-3.75)$ & 0.12 & - & - \\
\hline $\mathrm{N}^{\circ}$ of resected lymph nodes (continuous) & $1.00(0.93-1.07)$ & 0.89 & - & - \\
\hline Energy device (ultrasonic vs monopolar) & $1.03(0.53-2.01)$ & 0.93 & $1.52(0.71-3.24)$ & 0.28 \\
\hline Surgery duration (continuous) & $1.01(1.00-1.01)$ & 0.039 & $1.00(1.00-1.01)$ & 0.22 \\
\hline
\end{tabular}

$B M I$ body mass index, $\mathrm{Cl}$ confidence interval, $H R$ hazard ratio

observed a similar postoperative chylothorax rate using the conventional electrocautery or the Ligasure ${ }^{\mathrm{ma}}(1.61 \%$ vs $1.75 \%, p$-value $=1.00)$ [10]. Likewise, Yoshida et al. in their retrospective cohort of 112 patients did not detect any significant difference in terms of chylothorax incidence when small vessels division and lymph node dissection were performed by manual ligature and conventional electrocautery or by Ligasure ${ }^{\mathrm{mx}}(1.8 \%$ vs $0 \%$; $p$-value $=1.00)$ [4]. However, in our study and in that of Yoshida et al., chylothorax rate was slightly higher after using blunt instruments and electrocautery than with the vascular-sealing device. These results could be explained by the mechanical principles underlying the two techniques. In contrast to electrocautery sealing by heat coagulation only, the Harmonic ACE Plus ${ }^{\circ}$ combines heating and instrument blades mechanical pressure, fusing vessels walls and producing a permanent seal for vessels up to $5 \mathrm{~mm}[3-8,14,16,18,19]$. This sealing ability should prevent any oozing or lymphatic leak. However, the low incidence of chylothorax and the absence of statistically significant difference between the two groups suggest that careful use of electric hook can also lead to satisfying results in terms of lymphatic leakage control.

In our series the total amount of pleural effusion volume collected at $48 \mathrm{~h}$ after surgery was significantly higher after using the ultrasonic than the monopolar dissector. This result is in contrast with previous literature reports. Toishi et al., in their randomized study including 58 patients undergoing VATS lung lobectomy and lymph node dissection, reported significantly higher postoperative drainage volume when blunt dissection, manual ligature and/or electrocautery were preferred to vessels-sealing devices (Harmonic ACE Plus ${ }^{\circ}$, LigaSure ${ }^{\text {tm }}$ and Enseal $\left.{ }^{\circ}\right)(613 \pm 320$ vs $437 \pm 213 \mathrm{ml}$ at $48 \mathrm{~h}$; $p$-value $=$ 0.0358) [5]. Similar results were reported by Yoshida et al. comparing conventional tissue dissection and vascular ligation to the use of LigaSure ${ }^{\mathrm{Tm}}$ (postoperative drainage at $72 \mathrm{~h}: 705.3 \pm 339.3$ vs $533.8 \pm 264.8 \mathrm{ml} ; p$ value $<0.05$ ) [4]. In our study, the concurrence of other variables may explain the increased postoperative pleural effusion production with the Harmonic ACE Plus ${ }^{\circ}$. In fact, the multivariable analysis identified lower lung lobectomies and increased surgery duration, but not energy

Table 4 Energy devices safety and impact on postoperative course in the matched cohort of 56 patients

\begin{tabular}{|c|c|c|c|}
\hline Outcomes measures & $\begin{array}{l}\text { Group A } \\
(n=28)\end{array}$ & $\begin{array}{l}\text { Group B } \\
(n=28)\end{array}$ & $p$-value \\
\hline Intraoperative device related accident, n (\%) & $0(0)$ & $0(0)$ & 1.00 \\
\hline Surgery duration, median (IQR) minutes & $199(179-242)$ & $214(187-241)$ & 0.73 \\
\hline Postoperative hemothorax, n (\%) & $0(0)$ & $0(0)$ & 1.00 \\
\hline Postoperative chylothorax, n (\%) & $1(3)$ & $0(0)$ & 1.00 \\
\hline Pleural effusion volume during the first 48 postoperative hours, median (IQR) ml & $308(170-501)$ & $350(268-485)$ & 0.45 \\
\hline Chest tube duration, median (IQR) days & $4(3-7)$ & $5(3-8)$ & 0.46 \\
\hline Postoperative length of stay, median (IQR) days & $7(6-9)$ & $8(6-10)$ & 0.77 \\
\hline
\end{tabular}


device as risk factors for increased pleural effusion volume at $48 \mathrm{~h}$ after surgery. Moreover, after matching patients by gender, site of resection and surgeon, these differences were annulled.

Regarding chest tube duration, no differences were detected between electric hook and Harmonic ACE Plus ${ }^{\circ}$ in our study, even when energy device variable was adjusted for other possible risk factors for late chest tube removal at multivariable analysis. Thus, beside the two cases of chylothorax in monopolar electrocautery group and the larger amount of postoperative pleural drainage in Harmonic ACE Plus ${ }^{\circ}$ group, the use of one or the other instrument revealed a similar impact on postoperative chest tube duration. These findings are supported by the report of Schuchert et al., who did not observe any differences in terms of postoperative outcomes when Ligasure $^{\mathrm{Tw}}$ was used in 211 open and VATS anatomical lung resections [9]. No difference in chest tube removal timing has also been reported by Martucci et al. [10]. Conversely, Toishi et al. and Yoshida et al. reported earlier chest tube removal when vessel-sealing devices were used $[4,5]$. These differences could also be explained by the fact that vessel-sealing devices were not the same in the mentioned studies $[4,5,9,10]$. Data about postoperative prolonged air-leak, a relevant factor of delayed chest tube removal, were not reported $[4,5]$.

Surgical procedures lasted longer in the Harmonic ACE Plus ${ }^{\circ}$ group of our series, while previous studies did not observe any differences in the length of surgery using vessel-sealing instruments $[4,5]$. Considering these observations and our long-term favorable experience with Harmonic ACE Plus ${ }^{\oplus}$, longer duration of surgery in the ultrasonic dissector group was probably not due to the device itself but to the higher (almost double) proportion of lower lung lobectomies performed using this device type $(p$-value $=0.005)$; no difference of surgery duration was detected in the matched cohort.

Finally, in terms of costs, Harmonic ACE Plus is not reusable and is more expensive than the electric hook, which is also reusable; cost is about fourfold ( 130 vs 500 Euros) in our institution. Thus, in the absence of documented Harmonic ACE Plus ${ }^{\bullet}$ greater impact on the surgical procedure and on postoperative short-term outcomes, electric hook may be preferred with the aim of saving direct cost of the energy device. However, ultrasonic device sealing ability could reduce the use of endoscopic staplers and ligating clips, that are also costly, and may impact on overall surgical costs $[9,14,16,18,20]$.

This study has several limitations. First, it is an observational study with the choice of electric hook or Harmonic ACE Plus ${ }^{\circ}$ left to surgeon's preference. Nevertheless, we performed multivariable analysis and propensity score matching analysis to partly overcome the lack of randomization. Second, we did not analyze the Harmonic ACE Plus ${ }^{\circ}$ performance in sealing small vessels up to $5 \mathrm{~mm}$, because surgeons in our team preferred to employ endoscopic staplers or clips to close vessels not suitable for coagulation. A strength of this observational study is the evaluation and comparison of electric hook and Harmonic ACE Plus performance in the real-world daily practice of VATS major lung resections.

\section{Conclusions}

In the present observational study the use of either surgical monopolar electric hook or ultrasonic Harmonic ACE Plus ${ }^{\circ}$ dissector for adhesiolysis, hilar dissection and lymphadenectomy during VATS lobectomy was safe and did not influence postoperative pleural effusion production and chest tube duration. Further randomized and larger studies are needed in order to confirm our results.

\section{Abbreviations}

BMI: Body mass index; Cl: Confidence interval; COPD: Chronic obstructive pulmonary disease; $\mathrm{FEV}_{1}$ : Forced expiratory volume in $1 \mathrm{~s}$; HR: Hazard ratio; IQR: Interquartile range; VATS: Video-assisted thoracoscopic surgery

\section{Acknowledgements \\ none}

\section{Authors' contributions}

Al, LD designed the study. EN, MC, SD collected the data. MC, NR analyzed and interpreted the data. MC, LD, Al, NR wrote and revised the manuscript. All authors read and approved the final manuscript.

\section{Funding}

none

\section{Availability of data and materials}

The datasets used and analyzed during the current study are available from the corresponding author on reasonable request.

\section{Declarations}

Ethics approval and consent to participate

This study was approved by our University Hospital Ethic Committee and individual patient consent was obtained for each case.

Consent for publication

not applicable

\section{Competing interests}

The authors declare that they have no competing interests.

Received: 30 October 2020 Accepted: 11 March 2021

Published online: 20 March 2021

\section{References}

1. Goudie E, Tahiri M, Liberman M. Present and future application of energy devices in thoracic surgery. Thorac Surg Clin. 2016;26(2):229-36. https://doi. org/10.1016/j.thorsurg.2015.12.010.

2. Gonzalez-Rivas D. Total anatomic vascular dissection for lobectomy by using only energy devices. J Vis Surg. 2015;1:8.

3. White A, Kucukak S, Lee DN, Swanson SJ. Energy-based ligation of pulmonary vessels: a six-year experience with ultrasonic shears in videoassisted thoracoscopic lobectomy and segmentectomy. Ann Thorac Surg. 2016;101(4):1334-7. https://doi.org/10.1016/j.athoracsur.2015.10.070.

4. Yoshida K, Toishi M, Eguchi T, Saito G, Shiina T, Kondo A, et al. Feasibility of using a vessel sealing system in a human pulmonary lobectomy: a retrospective comparison of this procedure with or without a vessel sealing 
system. Ann Thorac Cardiovasc Surg. 2014;20(5):353-8. https://doi.org/10. 5761/atcs.oa.13-00014.

5. Toishi M, Yoshida K, Agatsuma H, Sakaizawa T, Eguchi T, Saito G, Hashizume M, Hamanaka K, Shiina T. Usefulness of vessel-sealing devices for $\leq 7 \mathrm{~mm}$ diameter vessels: a randomized controlled trial for human thoracoscopic lobectomy in primary lung cancer. Interact Cardiovasc Thorac Surg. 2014; 19(3):448-55. https://doi.org/10.1093/icvts/ivu176.

6. Watanabe A, Nakazawa J, Miyajima M, Harada R, Nakashima S, Mawatari T, Higami T. Thoracoscopic mediastinal lymph node dissection for lung cancer. Semin Thorac Cardiovasc Surg. 2012;24(1):68-73. https://doi.org/10.1 053/j.semtcvs.2012.03.002.

7. Goudie E, Oliveira RL, Thiffault V, Jouquan A, Lafontaine E, Ferraro P, Liberman M. Phase 1 trial evaluating safety of pulmonary artery sealing with ultrasonic energy in VATS lobectomy. Ann Thorac Surg. 2018;105(1):214-20. https://doi.org/10.1016/j.athoracsur.2017.08.013.

8. Liberman M, Goudie E, Morse C, Hanna W, Evans N, Yasufuku K, et al. Prospective, multicenter, international phase 2 trial evaluating ultrasonic energy for pulmonary artery branch sealing in video-assisted thoracoscopic surgery lobectomy. J Thorac Cardiovasc Surg. 2019;159:301-11.

9. Schuchert MJ, Abbas G, Pettiford BL, Luketich JD, Landreneau RJ. Preliminary results of anatomic lung resection using energy-based tissue and vessel coagulative fusion technology. J Thorac Cardiovasc Surg. 2010;140(5):116873. https://doi.org/10.1016/j.jtcvs.2010.06.064

10. Martucci N, Tracey M, La Rocca A, La Manna C, De Luca G, Rocco G. A pilot prospective randomized, controlled trial comparing LigaSure ${ }^{\mathrm{TM}}$ tissue fusion technology with the ForceTriad ${ }^{\text {TM }}$ energy platform to the electrosurgical pencil on rates of atrial fibrillation after pulmonary lobectomy and mediastinal lymphadenectomy. Eur J Cardiothorac Surg. 2015;47(1):e13-8. https://doi.org/10.1093/ejcts/ezu391.

11. Hansen HJ, Petersen RH. Video-assisted thoracoscopic lobectomy using a standardized three-port anterior approach - the Copenhagen experience. Ann Cardiothorac Surg. 2012;1(1):70-6. https://doi.org/10.3978/j.issn.2225-31 9X.2012.04.15.

12. Nduka CC, Super PA, Monson JR, Darzi AW. Cause and prevention of electrosurgical injuries in laparoscopy. J Am Coll Surg. 1994;179(2):161-70.

13. Overbey DM, Townsend NT, Chapman BC, Bennett DT, Foley LS, Rau AS, Yi JA, Jones EL, Stiegmann GV, Robinson TN. Surgical energy-based device injuries and fatalities reported to the food and drug administration. J Am Coll Surg. 2015;221(1):197-205. https://doi.org/10.1016/.jamcollsurg.2015.03.031.

14. Alkatout I, Schollmeyer T, Hawaldar NA. Principles and safety measures of electrosurgery in laparoscopy. JSLS. 2012;16(1):130-9. https://doi.org/10.42 93/108680812X13291597716348.

15. Družijanić N, Pogorelić Z, Perko Z, Mrklić I, Tomić S. Comparison of lateral thermal damage of the human peritoneum using monopolar diathermy, Harmonic scalpel and LigaSure. Can J Surg. 2012;55(5):317-21. https://doi. org/10.1503/cjs.000711

16. Hefermehl LJ, Largo RA, Hermanns T, Poyet C, Sulser T, Eberli D. Lateral temperature spread of monopolar, bipolar and ultrasonic instruments for robot-assisted laparoscopic surgery. BJU Int. 2014;114(2):245-52. https://doi. org/10.1111/bju.12498.

17. Sutton PA, Awad S, Perkins AC, Lobo DN. Comparison of lateral thermal spread using monopolar and bipolar diathermy, the Harmonic scalpel and the Ligasure. Br J Surg. 2010;97(3):428-33. https://doi.org/10.1002/bjs.6901.

18. Kondrup JD, Anderson F, Sylvester B, Branning M. The new HARMONIC ACE +7 shears: a game changer in ultrasonic hemostasis. Surg Technol Int. 2014;25:24-7.

19. Taheri A, Mansoori P, Sandoval LF, Feldman SR, Pearce D, Williford PM. Electrosurgery: part I. Basics and principles. J Am Acad Dermatol. 2014;70: 591.e1-591.e14.

20. Richardson MT, Backhus LM, Berry MF, Vail DG, Ayers KC, Benson JA, Bhandari P, Teymourtash M, Shrager JB. Intraoperative costs of videoassisted thoracoscopic lobectomy can be dramatically reduced without compromising outcomes. J Thorac Cardiovasc Surg. 2018;155(3):1267-77. https://doi.org/10.1016/j.jtcvs.2017.08.146.

\section{Publisher's Note}

Springer Nature remains neutral with regard to jurisdictional claims in published maps and institutional affiliations.

Ready to submit your research? Choose BMC and benefit from:

- fast, convenient online submission

- thorough peer review by experienced researchers in your field

- rapid publication on acceptance

- support for research data, including large and complex data types

- gold Open Access which fosters wider collaboration and increased citations

- maximum visibility for your research: over $100 \mathrm{M}$ website views per year

At BMC, research is always in progress.

Learn more biomedcentral.com/submissions 